УДК 616.379-008.64-06

DOI 10.11603/bmbr.2706-6290.2020.4.11827

У. П. Гевко ${ }^{1}$, І. Г. Дікова ${ }^{2}$ Х. Я. Максів ${ }^{1}$, С. В. Дзига ${ }^{1}$, О. В. Бакалець ${ }^{1}$, Н. Б. Бегош ${ }^{1}$ Тернопільський національний медичний університет імені I. Я. Горбачевського МОЗ Украйни ${ }^{1}$ Національний медичний університет імені О. О. Богомольия

\title{
ЦУКРОВИЙ ДІАБЕТ 2 ТИПУ ТА ЙОГО КОМОРБІДНІСТЬ
}

Цукровий діабет 2 типу та його коморбідність У. П. Гевко ${ }^{1}$, І. Г. Дікова², Х. Я. Максів ${ }^{1}$, С. В. Дзиґа ${ }^{1}$, О. В. Бакалець ${ }^{1}$ Н. Б. Бегош ${ }^{1}$

Тернопільський національний медичний університет імені І. Я. Горбачевського МОЗ України Національний медичний університет імені О. О. Богомольця²

Резюме. Цукровий діабет є складною проблемою охорони здоров'я, яка за останні кілька десятиліть викликає занепокоєння міжнародного рівня.

Мета дослідження - проаналізувати літературні джерела щодо коморбідних патологій, які поєднано перебігають з цукровим діабетом 2 типу (T2DM).

Матеріали і методи. У дослідженні опрацьовано наукові публікації за останнє десятиліття, які доступні у мережі «lнтернет», ключовими словами були: «цукровий діабет 2 типу», «коморбідність», «супутні захворювання».

Результати. Мультиморбідність, наявність двох або більше хронічних захворювань, $є$ характерним для пацієнтів з T2DM, що робить мультиморбідність у чій популяції важливим клінічним пріоритетом. Через схожі фрактори ризику, такі, як ожиріння, ендотеліальна дисфрункція, запалення судин та дисліпідемія, хворі на T2DM мають більш високий ризик серцево-судинних ускладнень, хвороб нирок та гіпертензії. Також у пацієнтів із T2DM встановлено більш високий ризик депресії, захворювань шлунково-кишкового тракту, щитоподібної залози та хронічного обструктивного захворювання легень. T2DM тісно пов'язаний із надмірною масою тіла та низькою фрізичною активністю. Ще одним ускладненням T2DM є еректильна дисфункція. Хоча більшість наукової літератури присвячена розвитку T2DM у хворих на панкреатит, існує й зворотна залежність: екзокринна недостатність підшлункової залози виявляється у $35 \%$ хворих на T2DM. Крім того, високий рівень дефріциту вітаміну $D \in$ ще одним фрактором, пов'язаним як із ожирінням, так і з діабетом 2 типу.

Висновки. Аналіз літературних джерел свідчить про значну поширеність коморбідності у хворих на цукровий діабет 2 типу, що обрунтовує необхідність детальнішого й всебічного дослідження механізмів розвитку поєднаної патології, особливостей перебігу, методів просрілактики, лікування та попередження ускладнень.

Ключові слова: цукровий діабет 2 типу; коморбідність; поширеність.
Type 2 diabetes mellitus and its comorbidity

U. P. Hevko${ }^{1}$, I. G. Dikova², Kh. Ya. Maksiv ${ }^{1}$, S. V. Dzyha ${ }^{1}$, O. V. Bakalets ${ }^{1}$, N. B. Behosh ${ }^{1}$

I. Horbachevsky Ternopil National Medical University ${ }^{1}$

O. Bohomolets National Medical University ${ }^{2}$

e-mail: bakalets@tdmu.edu.ua

Summary. Diabetes is a complex health problem that has caused international concern over the past few decades.

The aim of the study - to analyze the literature sources on comorbid pathologies that are combined with the type 2 diabetes mellitus (T2DM).

Materials and Methods. Scientific publications for the last decade was examined in the study, which are available in the Internet, the key words were "type 2 diabetes mellitus", "comorbidity", "concurrent diseases".

Results. Multimorbidity, presence of two or more chronic diseases [8], is characteristic for patients with T2DM, which makes multimorbidity an important clinical priority in this population. Because of similar risk factors such as obesity, endothelial dysfunction, vascular inflammation and dyslipidemia, patients with T2DM have higher risk of cardiovascular complications, kidney disease and hypertension. Patients with T2DM have also higher risk of depression, gastrointestinal disease, thyroid disease, and chronic obstructive pulmonary disease. T2DM is closely associated with overweight and low physical activity. Another complication of T2DM is erectile dysfunction. Although most of the scientific literature highlights development of T2DM in patients with pancreatitis, there is an inverse relations: exocrine insufficiency of the pancreas is found in $35 \%$ of patients with T2DM. In addition, high level of vitamin D deficiency is another factor associated with both obesity and type 2 diabetes mellitus.

Conclusions. Analysis of literature sources indicates significant prevalence of comorbidity in patients with type 2 diabetes mellitus, which justifies the necessity of more detailed and comprehensive study of the mechanisms of combined pathology, peculiarities of course, methods of precaution, treatment and prevention of complications.

Key words: type 2 diabetes mellitus; comorbidity; prevalence. 


\section{ВСТУП}

Цукровий діабет є складною проблемою охорони здоров'я, яка за останні кілька десятиліть викликає занепокоєння міжнародного рівня. Поширеність цукрового діабету в усьому світі зросла більш ніж удвічі серед чоловіків та в 1,6 раза серед жінок, охопивши понад 420 млн людей у 2014 р. [1]. У 2015 р. середня поширеність діабету в Європі становила 9,1\%, де у 87-91 \% випадків діагностували цукровий діабет 2 типу (T2DM) [2]. Протягом 2000-2017 pp. поширення діабету (як \% від населення) зросла в США з 3,9 до 5,8 \%, у Великобританії - 3 4,4 до 6,1 \%, в Польщі - 3 5,5 до 6,3 \% [3]. Поширеність цукрового діабету в Україні становить 3,5 млн осіб, при цьому кількість осіб із встановленим діагнозом - 1,23 млн (35 \% від усіх осіб з діабетом) [4]. Епідеміологічні дослідження вказують на постійне збільшення числа хворих на цукровий діабет серед населення України в середньому на 5-7 \% щорічно. Потрібно також врахувати, що T2DM діагностують у все більш молодого населення - в світі кількість нових випадків діабету серед населення молодше 40 років зростає зі значною швидкістю - на 9 \% щорічно [5]. За прогнозами, до 2040 р. поширеність цукрового діабету зросте до $642 \mathrm{Mлн,} \mathrm{і} \mathrm{найбільше}$ підвищення відбудеться у регіонах, які переживають економічний перехід [2]. Потрібно також розуміти, що точність та надійність таких екстраполяцій можуть бути сумнівними через відсутність статистичних даних ряду країн. Так, кількість хворих на цукровий діабет у всьому світі у 2015 р. вже набагато перевищила прогнозовану в 2000 р. на 2030 р. як за даними International Diabetes Federation (324 млн), так і ВОО3 (366 млн). Щорічно діабет та його ускладнення призводять до понад 2 млн смертей у всьому світі [1]. Окрім медико-соціального значення досліджені також економічні витрати на цукровий діабет, які у 2015 р., за даними С. Bommer et al., ста; новили 13,1 трлн дол. США [6]. Загальні втрати економіки діабету та його ускладнень в Україні складають 36-104 млрд грн на рік (1-2,5 \% ВВП) [4].

Метою дослідження було проаналізувати літературні джерела щодо коморбідних патологій, які поєднано перебігають з цукровим діабетом 2 типу.

\section{МАТЕРІАЛИ I МЕТОДИ}

У дослідженні опрацьовано наукові публікації за останнє десятиліття, які доступні у мережі «Інтернет», ключовими словами були: «цукровий діабет 2 типу», «коморбідність», «супутні захворювання».

\section{РЕЗУЛЬТАТИ Й ОБГОВОРЕННЯ}

T2DM $€$ багатофракторним генетичним захворюванням, яке спричиняє значну захворюваність та смертність у всьому світі [7]. Мультиморбідність, наявність двох або більше хронічних захворювань [8] є характерними для пацієнтів із T2DM, що роа бить мультиморбідність у цій популяції важливим клінічним пріоритетом. За статистичними даними Австралії, діабетичні ускладнення виявлено у понад $80 \%$ хворих, при цьому майже у 50 \% пацієнтів було два або більше ускладнень, найчастішим одиничним ускладненням була ретинопатія, а дальше ішемічна хвороба серця [9]. Nowakowska et al. виявили, що майже 75 \% пацієнтів мали принаймні одну додаткову супутню патологію на момент діагностики T2DM, a 44 \% - щонайменше дві супутні патології [10]. Інші дослідження вказують на діабетичні ускладнення у 90 \% [11] , 91,4 \% [12], 84,6 \% [13], 44 \% [14] хворих на T2DM, що ймовірно залежить від вікової і гендерної охопленості респондентів у дослідження.

Через схожі фрактори ризику, такі, як ожиріння, ендотеліальна диссрункція, запалення судин та дисліпідемія [15], хворі на T2DM мають більш високий ризик серцево-судинних ускладнень [16, 17], хвороби нирок [18] та гіпертензії [19]. Також у пацієнтів із T2DM встановлено більш високий ризик депресії [20], захворювань шлунково-кишкового тракту [21], щитоподібної залози [22, 23] та хронічного обструктивного захворювання легень [24, 25]. Т2DM тісно пов'язаний із надмірною масою тіла та низькою фрізичною активністю. Показано, що 86 \% дорослих осіб з T2DM мають зайву масу або страждають від ожирінням, 3 них 52 \% мають ожиріння та 8,1\% - морбідне ожиріння [26]. 3 іншого боку, Т2DМ виявляється у 90-95\% пацієнтів 3 ожирінням, при цьому протягом багатьох років захворювання не діагностують через поступовий розвиток гіперглікемії [27]. Хоча більшість наукової літератури присвячена розвитку T2DM у хворих на панкреатит [28], існує й зворотна залежність: екзокринна недостатність підшлункової залози виявляється у $35 \%$ хворих на T2DM [29]. Крім того, високий рівень дефріциту вітаміну D $€$ ще одним фрактором, пов'язаним як із ожирінням, так і з T2DM [30].Також вищий ризик захворювання нирок у хворих на T2DM також пов'язаний із вмістом вітаміну $25(\mathrm{OH})$ D у сироватці крові в 66 \% пацієнтів [31]. За даними K. Ekoru et al., найпоширенішими супутніми захворюваннями при T2DM були гіпертензія (приблизно у трьох із чотирьох осіб), проблеми із зором (у кожної другої особи), гіперліпідемія та ожиріння (кожен третій пацієнт) [32]. Результати дослідження турецьких вчених показали, що найпоширенішими супутніми захворюваннями у хворих на Т2DM були гіпертензія (84,9\%) та гіперліпідемія (65,6\%), поширеність ожиріння становила 54,4 \%, нефропатії - 36,6 \%, ішемічної хвороби серця - 22,8 \%, ретинопатії - 18,5\%, інсульту - 4,8 \% [33]. При цьому вік, тривалість
ISSN 2706-6282(print)

ISSN 2706-6290(online)
Вісник медичних і біологічних досліджень Bulletin of Medical and Biological Research
$4(6), 2020$ 
діабету та вживання інсуліну суттєво пов'язані 3 усіма супутніми захворюваннями. Встановлено, що жінки з T2DM мають меншу ймовірність виникө нення серцево-судинних захворювань та хронічної хвороби нирок та більшу поширеність депресії [12]. Зниження поширеності бронхіальної астми у хворих на T2DM може бути пов'язане з кореляв цією між вживанням метформіну та зменшенням загострень астми [34]. Оскільки T2DM сильно корелює з ожирінням, як і астма [35] та депресія [36], пацієнти після діагностики T2DM працюють у напрямку зниження свого індексу маси тіла (IMT), що одночасно впливає й на інші захворювання. Ще одним ускладненням T2DM $€$ еректильна дисфрункція (близько 35 \% чоловіків) [37] як наслідком дисфункції ендотелію та мікроангіопатій, гіпертензії або антигіпертензивного лікування [38]. Загалом, поширеність мікросудинних ускладнень майже вдвічі більша порівняно 3 макросудинними ускладненнями (20,41 проти 10,20 \%) [39].

\section{СПИСОК ЛІТЕРАТУРИ}

1. NCD-RisC. Worldwide trends in diabetes since 1980: a pooled analysis of 751 populationbased studies with 4.4 million participants // Lancet. - 2016. - No. 387. - P. 1513-1530.

2. IDF. International Diabetes Federation. IDF Diabetes Atlas, 7th edn. Belgium. -2015

3. Global Burden of Disease database. Institute for health metrics and evaluation, Seattle, Washington. - 2017.

4. Аналіз системи лікування та розрахунок економічних втрат від цукрового діабету в Україні. Київ. - 2020.

5. Type 2 diabetes in adolescents and young adults / N. Lascar, J. Brown, H. Pattison [et al.] // Lancet Diabetes Endocrinol. - 2018. - No. 6 (1). - P. 69-80.

6 . The global economic burden of diabetes in adults aged 20-79 years: a cost-of-illness study / C. Bommer, F. Heesemann, V. Sagalova [et al.] // Lancet Diabetes Endocrinol. - 2017. - No. 8587 (17). - P. 1-8.

7. Association of comorbid and metabolic factors with optimal control of type 2 diabetes mellitus / S. Roy, A. Sherman, M. J. Monari-Sparks [et al.] // N. Am. J. Med. Sci. - 2016. - No. 8 (1). - P. 31-39.

8. Relationship between multimorbidity, demographic factors and mortality: findings from the UK Biobank cohort / B. D. Jani, P. Hanlon, B. I. Nicholl [et al.] // BMC Med. 2019. - No. 17 (1). - P. 74.

9. Australian Bureau of Statistics. National Health Survey: First Result, 2014-15. Canberra, Australia: Australian Bureau of Statistics. 2015.

10. The comorbidity burden of type 2 diabetes mellitus: patterns, clusters and predictions from a large English primary care cohort / M. Nowakowska, S. S. Zghebi, D. M. Ashcroft [et al.] // BMC Medicine. - 2019. - No.17. - P. 145.

11. Multimorbidity in a cohort of patients with type 2 diabetes / C. Teljeur, S. M. Smith, G. Paul [et al.] // Eur. J. Gen. Pract. - 2013. - No. 19 (1). - P. 17-22.

12. The prevalence of diabetes-related complications and multimorbidity in the population with type 2 diabetes mellitus in the Basque Country / E. Lonso-Morán,
Незважаючи на велику кількість досліджень, T2DM продовжує залишатись вагомою причиною смертності [40], а також великої кількості ускладнень. Очевидно, що T2DM є погано контрольованою епідемією, яка вимагає активних досліджень механізмів розвитку, особливостей перебігу, методів профрілактики, лікування та попередження усклада нень. Оскільки патогенез T2DM багатогранний та стосується безлічі патофрізіологічних аберацій, необхідно детальніше і глибше вивчити особливості патогенезу $[16,41]$.

\section{ВИСНОВКИ}

Аналіз літературних джерел свідчить про значну поширеність коморбідності у хворих на цукровий діабет 2 типу, що обґрунтовує необхідність детальнішого й всебічного дослідження механізмів розвитку поєднаної патології, особливостей перебігу, методів профрілактики, лікування та попередження ускладнень.

J. F. Orueta, J. I. F. Esteban [et al.] // BMC Public Health. 2014. - No. 14. - P. 1059.

13. Prevalence and incidence density rates of chronic comorbidity in type 2 diabetes patients: an exploratory cohort study / H. Luijks, T. Schermer, H. Bor. [et al.] // BMC Med. - 2012. - No. 10 (1). - P. 128.

14. Comorbidity in patients with diabetes mellitus: impact on medical health care utilization / J. N. Struijs, C. A. Baan, F. G. Schellevis [et al.] // BMC Health Serv Res. - 2006. - No. 6. - P. 84.

15. Petrie J. R. Diabetes, hypertension, and cardiovascular disease: clinical insights and vascular mechanisms / J. R. Petrie, T. J. Guzik, R. M. Touyz // Can. J. Cardiol. - 2018. - No. 34 (5). - P. 575-584.

16. Diabetes mellitus, fasting blood glucose concentration, and risk of vascular disease: a collaborative meta-analysis of 102 prospective studies / Emerging Risk Factors Collaboration, N. Sarwar, P. Gao, S. R. K. Seshasai [et al.] // Lancet. - 2010. - No. 375 (9733). - P. 2215-2222.

17. Максів Х. Я. Патогенез артеріальної гіпертензії: роль окиснювальних процесів / Х. Я. Максів, М. І. Марущак // Вісник медичних і біологічних досліджень. - 2020. - № 2. - C. 81-87.

18. United States Renal Data System. International comparisons. In: United States Renal Data System. USRDS annual data report: epidemiology of kidney disease in the United States. Bethesda: National Institutes of Health, National Institute of Diabetes and Digestive and Kidney Diseases. - 2014.

19. Waeber B. Diabetes and hypertension / B. Waeber, F. Feihl, L. Ruilope // Blood Press. - 2001. - No. 10 (5-6). - P. 311-321.

20. Association of depression and diabetes complications: a meta-analysis / M. De Groot, R. Anderson, K. E. Freedland [et al.] // Psychosom. Med. - 2001. No. 63 (4). - P. 619-630.

21. Marushchak M. I. The features of oxidative 
processes in the wall of small intestine in rats with chronic enterocolitis combined with experimental diabetes / M. I. Marushchak, N. V. Lisnyanska, I. Y. Krynytska // Azerbaijan Medical Journal. - 2019. - No. 1. - P. 102-106.

22. Vondra K. Thyroid gland diseases in adult patients with diabetes mellitus/K. Vondra, J. Vrbikova, K. Dvorakova// Minerva Endocrinol. - 2005. - No. 30 (4). - P. 217-236.

23. Мусієнко В. А. Цукровий діабет 2 типу та захворювання щитоподібної залози: пошук спільних механізмів / В. А. Мусієнко, М. І. Марущак // Вісник медичних і біологічних досліджень. - 2020. - № 1. - С. 74-82.

24. Prevalence of major comorbidities in subjects with COPD and incidence of myocardial infarction and stroke: a comprehensive analysis using data from primary care / J. R. Feary, L. C. Rodrigues, C. J. Smith [et al.] // Thorax. 2010. - No. 65 (11). - P. 956-962.

25. Marushchak M. ACE gene I/D polymorphism and arterial hypertension in patients with COPD / M. Marushchak, Kh. Maksiv, I. Krynytska // Pneumologia. - 2019. - No. 68 (3). - P. 114-119.

26. Obesity and Type 2 Diabetes Mellitus / A. S. A. Saboor, N. Reddy, E. Smith [et al.] // Intern. Med. 2014. - P. 6.

27. Albarakat M. Prevalence of type 2 diabetes and their complications among home health care patients at AlKharj military industries corporation hospital / M. Albarakat, A. Guzu // J. Family Med. Prim. Care. - 2019. - No. 8 (10). - P. 3303-3312.

28. Chronic pancreatitis and diabetes mellitus / Y. K. Lin, P. C. Johnston, K. Arce // Current Treatment Options in Gastroenterology. - 2015. - No. 13 (3). - P. 319-331.

29. High prevalence of exocrine pancreatic insufficiency in diabetes mellitus. A multicenter study screening fecal elastase 1 concentrations in 1,021 diabetic patients / P. D. Hardt, A. Hauenschild, J. Nalop [et al.] // Pancreatology. - 2003. - No. 3 (5). - P. 395-402.

30. Pourshahidi L. K. Vitamin D and obesity: current perspectives and future directions / L. K. Pourshahidi // Proc. Nutr. Soc. - 2015. - No. 74. - P. 115-124.

\section{REFERENCES}

1. NCD-RisC. Worldwide trends in diabetes since 1980: a pooled analysis of 751 population based studies with 4.4 million participants. Lancet. 2016;387: 1513-30.

2. IDF. International Diabetes Federation. IDF Diabetes Atlas, 7th edn. Belgium. 2015.

3. Global Burden of Disease database. Institute for health metrics and evaluation, Seattle, Washington. 2017.

4. [Analysis of the treatment system and calculation of economic losses from diabetes in Ukraine]. Kyiv; 2020. Ukrainian.

5. Lascar N, Brown J, Pattison H, Barnett AH, Bailey CJ, Bellary S. Type 2 diabetes in adolescents and young adults. Lancet Diabetes Endocrinol. 2018;6(1): 69-80.

6. Bommer C, Heesemann E, Sagalova V, ManneGoehler J, Atun R, Bärnighausen T, Vollmer S. The global economic burden of diabetes in adults aged 20-79 years: a cost-of-illness study. Lancet Diabetes Endocrinol. 2017;8587(17): 1-8.

7. Roy S, Sherman A, Monari-Sparks MJ, Schweiker
31. Williams S. Vitamin D and chronic kidney disease / S. Williams, K. Malatesta, K. Norris // Ethn. Dis. - 2009. No. 19. - P. 5.

32. Type 2 diabetes complications and comorbidity in Sub-Saharan Africans / K. Ekoru, A. Doumatey, A. R. Bentley [et al.] // E. Clinical Medicine. - 2019. No. 16. - P. 30-41.

33. Akın S. Prevalence of comorbidities in patients with type-2 diabetes mellitus / S. Akın, C. Bölük // Primary Care Diabetes. - 2020. - Vol. 14 (5). - P. 431-434.

34. Forno E. Asthma in adults with diabetes: treat their diabetes with metformin, improve their asthma? / E. Forno // Respirology. - 2016. - No. 21 (7). - P. 1144-1145.

35. Hjellvik $\mathrm{V}$. Body mass index as predictor for asthma: acohort study of 118,723 males and females / V. Hjellvik, A. Tverdal, K. Furu // Eur. Respir. J. - 2010. - No. 35 (6). P. $1235-1242$.

36. Effect of body mass index on depression in a UK cohort of 363037 obesepatients: A longitudinal analysis of transition / O. M. Moussa, M. Ardissino, P. Kulatilake [et al.] // Clinical Obesity. - 2019. - No. 9.

37. Maiorino M. I. Diabetes and sexual dysfunction: current perspectives / M. I. Maiorino, G. Bellastella, K. Esposito // Diabetes Metab. Syndr. Obes. - 2014. No. 7. - P. 95-105.

38. Manolis A. Antihypertensive treatment and sexual dysfunction / A. Manolis, M. Doumas // Curr. Hypertens. Rep. - 2012. - No. 14. - 285-329.

39. Clinical profiles, comorbidities and complications of type 2 diabetes mellitus in patients from United Arab Emirates / H. F. Jelinek, W. M. Osman, A. H. Khandoker [et al.] // BMJ Open Diabetes Research and Care. - 2017. - No. 5.

40. Trends in the leading causes of death in the United States, 1970-2002 / A. Jemal, E. Ward, Y. Hao [et al.] // JAMA. - 2005. - No. 294. - P. 1255-1259.

41. Management of type 2 diabetes: New and future developments in treatment / A. A. Tahrani, C. J. Bailey, S. Del prato [et al.] // Lancet. - 2011. - No. 378. - P. 182-197.

O, Jain N, Sims E, Breda M, et al. Association of comorbid and metabolic factors with optimal control of type 2 diabetes mellitus. N Am J Med Sci. 2016;8(1): 31-39.

8. Jani BD, Hanlon P, Nicholl BI, McQueenie R, Gallacher KI, Lee D, Mair FS. Relationship between multimorbidity, demographic factors and mortality: findings from the UK Biobank cohort. BMC Med. 2019;17(1): 74.

9. Australian Bureau of Statistics. National Health Survey: First Result, 2014-15. Canberra, Australia: Australian Bureau of Statistics. 2015.

10. Nowakowska M, Zghebi SS, Ashcroft DM, Buchan I, Chew-Graham C. The comorbidity burden of type 2 diabetes mellitus: patterns, clusters and predictions from a large English primary care cohort. BMC Medicine. 2019;17: 145.

11. Teljeur C, Smith SM, Paul G, Kelly A, O'Dowd T. Multimorbidity in a cohort of patients with type 2 diabetes. Eur J Gen Pract. 2013;19(1): 17-22.

12. Lonso-Morán E, Orueta JF, Fraile Esteban JI, 
ArteagoitiaAxpe JM, Marqués González ML, Toro Polanco N, Ezkurra Loiola P, et al. The prevalence of diabetes-related complications and multimorbidity in the population with type 2 diabetes mellitus in the Basque Country. BMC Public Health. 2014;14: 1059 .

13. Luijks H, Schermer T, Bor H, van Weel C, LagroJanssen T, Biermans $M$, de Grauw W. Prevalence and incidence density rates of chronic comorbidity in type 2diabetes patients: an exploratory cohort study. BMC Med. 2012;10(1): 128.

14. Struijs JN, Baan CA, Schellevis FG, Westert GP, van den Bos GAM. Comorbidity in patients with diabetes mellitus: impact on medical health care utilization. BMC Health Serv Res. 2006;6: 84.

15. Petrie JR, Guzik TJ, Touyz RM. Diabetes, hypertension, and cardiovascular disease: clinical insights and vascular mechanisms. Can J Cardiol. 2018;34(5): 57584.

16. Emerging Risk Factors Collaboration, Sarwar N, Gao P, Seshasai SR, Gobin R, Kaptoge S, Di Angelantonio $E$, Ingelsson $E$, et al. Diabetes mellitus, fasting blood glucose concentration, and risk of vascular disease: a collaborative meta-analysis of 102 prospective studies. Lancet. 2010;375(9733): 2215-22.

17. Maksiv KhY, Marushchak MI. [Pathogenesis of arterial hypertension: the role of oxidative processes]. Visnyk medychnykh i biolohichnykh doslidzhen. 2020;2: 817. Ukrainian.

18. United States Renal Data System. International comparisons. In: United States Renal Data System. USRDS annual data report: epidemiology of kidney disease in the United States. Bethesda: National Institutes of Health, National Institute of Diabetes and Digestive and Kidney Diseases. 2014.

19. Waeber B, Feihl F, Ruilope L. Diabetes and hypertension. Blood Press. 2001;10(5-6): 311-21.

20. De Groot M, Anderson $R$, Freedland KE, Clouse $\mathrm{RE}$, Lustman PJ. Association of depression and diabetes complications: a meta-analysis. Psychosom Med. 2001;63(4): 619-30.

21. Marushchak MI, Lisnyanska NV, Krynytska IY. The features of oxidative processes in the wall of small intestine in rats with chronic enterocolitis combined with experimental diabetes. Azerbaijan Medical Journal. 2019;1: 102-6.

22. Vondra K, Vrbikova J, Dvorakova K. Thyroid gland diseases in adult patients with diabetes mellitus. Minerva Endocrinol. 2005;30(4): 217-36.

23. Musiienko VA, Marushchak MI. [Type 2 diabetes mellitus and thyroid disease: search for common mechanisms]. Visnyk medychnykh i biolohichnykh doslidzhen. 2020;1: 74-82. Ukrainian.

24. Feary JR, Rodrigues LC, Smith CJ, Hubbard RB, Gibson JE. Prevalence of major comorbidities in subjects with COPD and incidence of myocardial infarction and stroke: a comprehensive analysis using data from primary care. Thorax. 2010;65(11): 956-62.
25. Marushchak M, Maksiv Kh. Krynytska I. ACE gene I/D polymorphism and arterial hypertension in patients with COPD. Pneumologia. 2019;68(3): 114-9.

26. Saboor Aftab SA, Reddy N, Smith E, Barber TM. Obesity and type 2 diabetes mellitus. Intern Med. 2014;6.

27. Albarakat M, Guzu A. Prevalence of type 2 diabetes and their complications among home health care patients at Al-Kharj military industries corporation hospital. J Family Med Prim Care. 2019;8(10): 3303-12.

28. Lin YK, Johnston PC, Arce K, Hatipoglu BA. Chronic pancreatitis and diabetes mellitus. Current Treatment Options in Gastroenterology. 2015;13(3): 319-31.

29. Hardt PD, Hauenschild A, Nalop J, Marzeion AM, Jaeger C, Teichmann J, Bretzel RG, et al. High prevalence of exocrine pancreatic insufficiency in diabetes mellitus. A multicenter study screening fecal elastase 1concentrations in 1,021 diabetic patients. Pancreatology. 2003;3(5): 395402.

30. Pourshahidi LK. Vitamin D and obesity: current perspectives and future directions. Proc Nutr Soc. 2015;74: 115-24.

31. Williams S, Malatesta K, Norris K. Vitamin D and chronic kidney disease. Ethn Dis. 2009;19: 5

32. Ekoru K, Doumatey A, Bentley AR, Chen G, Zhou J, Shriner D, Fasanmade O, et al. Type 2 diabetes complications and comorbidity in Sub-Saharan Africans. E Clinical Medicine. 2019;16: 30-41.

33. Akın S, Bölük C. Prevalence of comorbidities in patients with type-2 diabetes mellitus. Primary Care Diabetes. 2020;14(5): 431-4.

34. Forno E. Asthma in adults with diabetes: treat their diabetes with metformin, improve their asthma? Respirology. 2016;21(7): 1144-5.

35. Hjellvik V, Tverdal A, Furu K. Body mass index as predictor for asthma: acohort study of 118,723 males and females. Eur Respir J. 2010;35(6): 1235-42.

36. Moussa OM, Ardissino M, Kulatilake P, Priyantha FA, Muttoni E, Darzi A, Ziprin P, et al. Effect of body mass index on depression in a UK cohort of 363037 obesepatients: A longitudinal analysis of transition. Clinical Obesity. 2019;9.

37. Maiorino MI, Bellastella G, Esposito K. Diabetes and sexual dysfunction: current perspectives. Diabetes Metab Syndr Obes. 2014; 7: 95-105.

38. Manolis A, Doumas M. Antihypertensive treatment and sexual dysfunction. Curr Hypertens Rep. 2012;14: 28592.

39. Jelinek HF, Osman WM, Khandoker AH, Khalaf K, Lee S, Almahmeed W, Alsafar HS. Clinical profiles, comorbidities and complications of type 2 diabetes mellitus in patients from United Arab Emirates. BMJ Open Diabetes Research and Care. 2017;5.

40. Jemal A, Ward E, Hao Y, Thun M. Trends in the leading causes of death in the United States, 1970-2002. JAMA. 2005;294: 1255-9.

41. Tahrani AA, Bailey CJ, Del prato S, Barnett $\mathrm{AH}$. Management of type 2 diabetes: New and future developments in treatment. Lancet. 2011;378: 182-97. 